\title{
Implementation of CHAMEN by means of Passivity Concept on Methanol Solvent Process
}

\author{
Opor Laosiriwut, Varintorn Athithunchaiyaphong, Thongchai Rohitatisha Srinophakun* \\ Department of Chemical Engineering, Faculty of Engineering, Kasetsart University, \\ Bangkok, 10900, Thailand. \\ ${ }^{*}$ Corresponding author, e-mail: fengtcs [AT] ku.ac.th
}

\begin{abstract}
This article mainly focuses on the application of the combined heat and mass exchanger network (CHAMEN) on Methanol solvent process. CHAMEN analyses heat exchanger network (HEN) and mass exchange network (MEN); simultaneously. HEN was designed by Aspen Energy Analyzer, while MEN was analyzed by GAMS. Then, optimal controllers were designed by the passivity concept to guarantee the general process stability. The dynamic model was generated for all variables of the unit in the state space domain. Subsequently, the state space model of CHAMEN was formulated investigated by the concept of passivity. Analyses by the passivity index can indicate the passivity of process. Also, this process with HEN and CHAMEN was investigated the performance of the system with and without controllers. Moreover, the responsibility of controllers was analyzed based on the concept of passivity and compared with auto tune method by Aspen Dynamic. Likewise, the passivity tune presented the better robust control over conservation method by auto tune. Finally, we explored future challenges in this field of apply to another process.
\end{abstract}

Keywords- Combined heat and mass exchanger network, Controllability, Methanol solvent process, Passivity concept

\section{INTRODUCTION}

At presently, chemical industries concern about the efficiency of mass and energy due to the continuously rising price of materials and energy. Therefore, intensification process for example HEN and MEN to minimize pollution, it recovers valuable materials and energy by maintaining product specification has been of interest [1]. Especially, energy and mass integration has been identified as powerful tools for improving processes. HEN and MEN can be integrated to CHAMEN which provide a meaningful improvement over the synthesis of individual network. CHAMEN was synthesized by using vary methods, such as pinch technology [2], interval-based MINLP superstructure (IBMs) [3], state space approach [4], and supply-based superstructure [5].

The chemical plant has 3 decision steps that are the structure of the plant, operational parameters, and control structure in order to design the networks [6]. Moreover, the control structure plays a major role on controllability of process [7]. Thus, the important factor that use to design and evaluation chemical processes are the control structure selection. This selection has many methods to simplify such as a relative gain array [8], disturbance cost [9], passivity [10], controllability index [11], and others.

The environmental issue has been a serious challenge due to the rapid economic growth which caused the increase of acid gas. Thus, there are many technologies and method for instant, absorption separation technology and membrane separation technology [12]. Solvent absorption method is physical absorption and chemical absorption. The physical absorption is widely acceptable due to the low operation cost, high solubility, and selectivity. Therefore, the separating agent which is methanol is generally used in acid gas removal such as, $\mathrm{CO}, \mathrm{CO}_{2}$, hydrogen sulfide $\left(\mathrm{H}_{2} \mathrm{~S}\right)$ and carbonyl sulfide (COS). Methanol is the most popular to eliminate these acid gas because it can be operated at low temperatures and high pressure which increased acid gas solubility [13].

Consequently, this work presented the synthesis of CHAMEN with the methanol solvent process. The pinch technology was used for HEN synthesis and MINLP technique was used for MEN design. Moreover, the passivity concept was applied to these networks for testing the stability of the system, as well as compared to auto tune.

\section{METHODOLOGY}

\subsection{Methanol solvent process}

The case study that used in this research is Methanol solvent process (Aspen Tech) which consists of four absorbers and seven separators as showed in Figure 1. Also, it has heater, cooler, pump, mixer and separator. This process used 
methanol as absorbent as well as absorbate was acid gas. The acid gas consists of carbon dioxide $\left(\mathrm{CO}_{2}\right)$, hydrogen sulfide $\left(\mathrm{H}_{2} \mathrm{~S}\right)$, carbonyl sulfide (COS) and carbon disulfide $\left(\mathrm{CS}_{2}\right)$. Thus, this process mainly focus on the absorption of the acid gas by using methanol solvent and obtain the pure gas which mostly composes of carbon monoxide (CO).

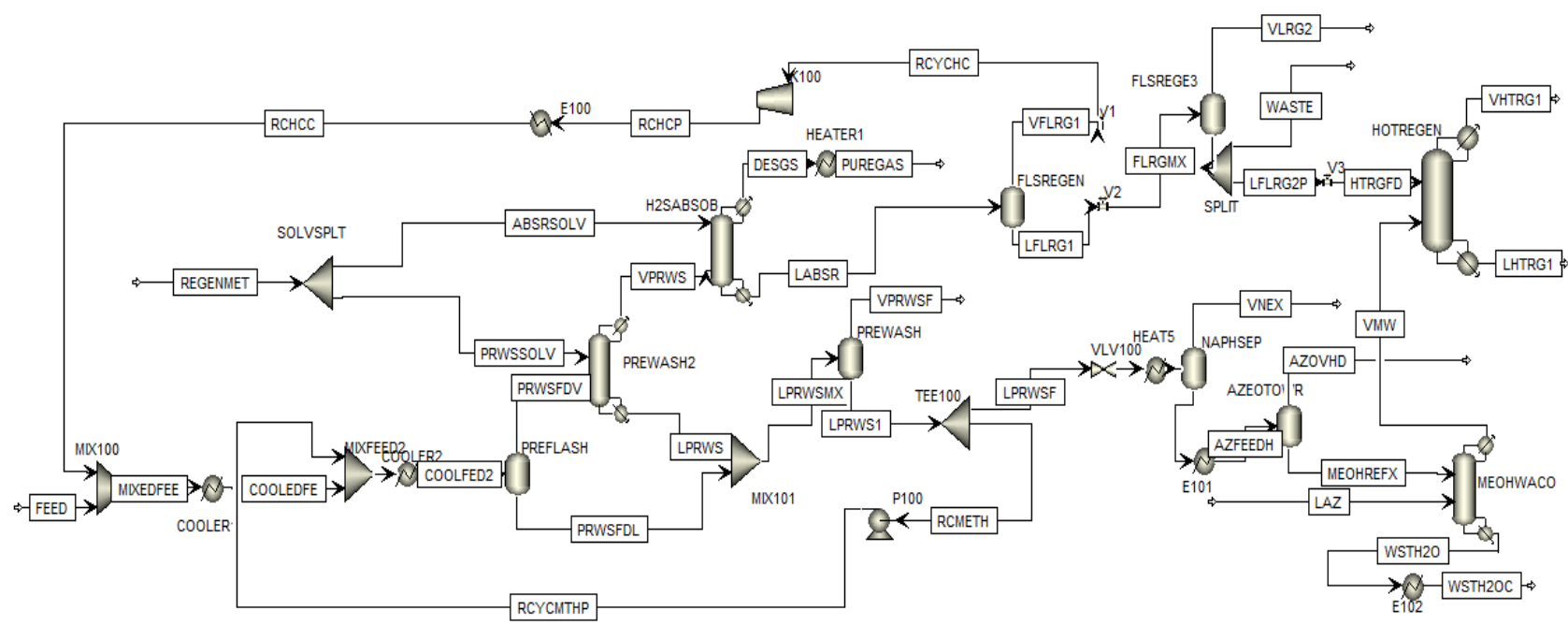

Figure 1: Study case of methanol solvent process from Aspen Tech

\subsection{Combined heat and mass exchanger network (CHAMEN)}

Considering of CHAMEN, heat exchanger network and mass exchanger network was separately designed. Heat exchanger network was approached based on Pinch technology, but the mass exchanger network was formulated by MINLP algorithm.

\subsubsection{Heat exchanger network (HEN)}

A general heat exchanger model was developed from the dynamic model of a single heat exchanger. The model is consisted of a set of ordinary differential equation (ODE) with the following assumption; no phase changes, constant densities of the two fluids, constant specific heat capacities of the two fluids, constant thermal efficiency, constant and flow independent, heat transfer coefficient and lumped models [14]. The dynamic models for heat exchanger was showed in eqs. (1) and (2) for cold side and hot side, respectively.

$$
\begin{gathered}
\frac{\partial T_{C}}{\partial t}=\frac{F_{C}}{V_{C}}\left(T_{C, i n}-T_{C}\right)+\frac{U A}{\rho_{C} V_{C} C_{v, C}}\left(T_{H}-T_{C}\right) \\
\frac{\partial T_{H}}{\partial t}=\frac{F_{H}}{V_{H}}\left(T_{H, i n}-T_{H}\right)-\frac{U A}{\rho_{H} V_{H} C_{v, H}}\left(T_{H}-T_{C}\right)
\end{gathered}
$$

\subsubsection{Mass exchanger network (MEN)}

The dynamic model of mass exchanger which is eqs. (3) and (4) was developed based on a single mass exchanger and following assumption; lump parameter system, both rich and lean streams are well mixed, linear equilibrium relations, constant mass exchange, isothermal, and isobaric.

$$
\begin{gathered}
\frac{d y_{\text {out }}}{d t}=\frac{2 m G-K A}{2 m M_{G}} y_{\text {in }}+\frac{-2 m G-K A}{2 m M_{G}} y_{\text {out }}+\frac{K A}{2 M_{G}} x_{\text {in }}+\frac{K A}{2 M_{G}} x_{\text {out }} \\
\frac{d x_{\text {out }}}{d t}=\frac{2 m L-K A}{2 m M_{L}} x_{\text {in }}+\frac{-2 m L-K A}{2 m M_{L}} x_{\text {out }}+\frac{K A}{2 M_{L}} y_{\text {in }}+\frac{K A}{2 M_{L}} y_{\text {out }}
\end{gathered}
$$




\subsection{Passivity concept}

This concept was used to analyze the stability of the system. The passivity method is divided into three parts which are passivity index, a passivity controller and state space. The passivity concept is illustrated in Figure 2.

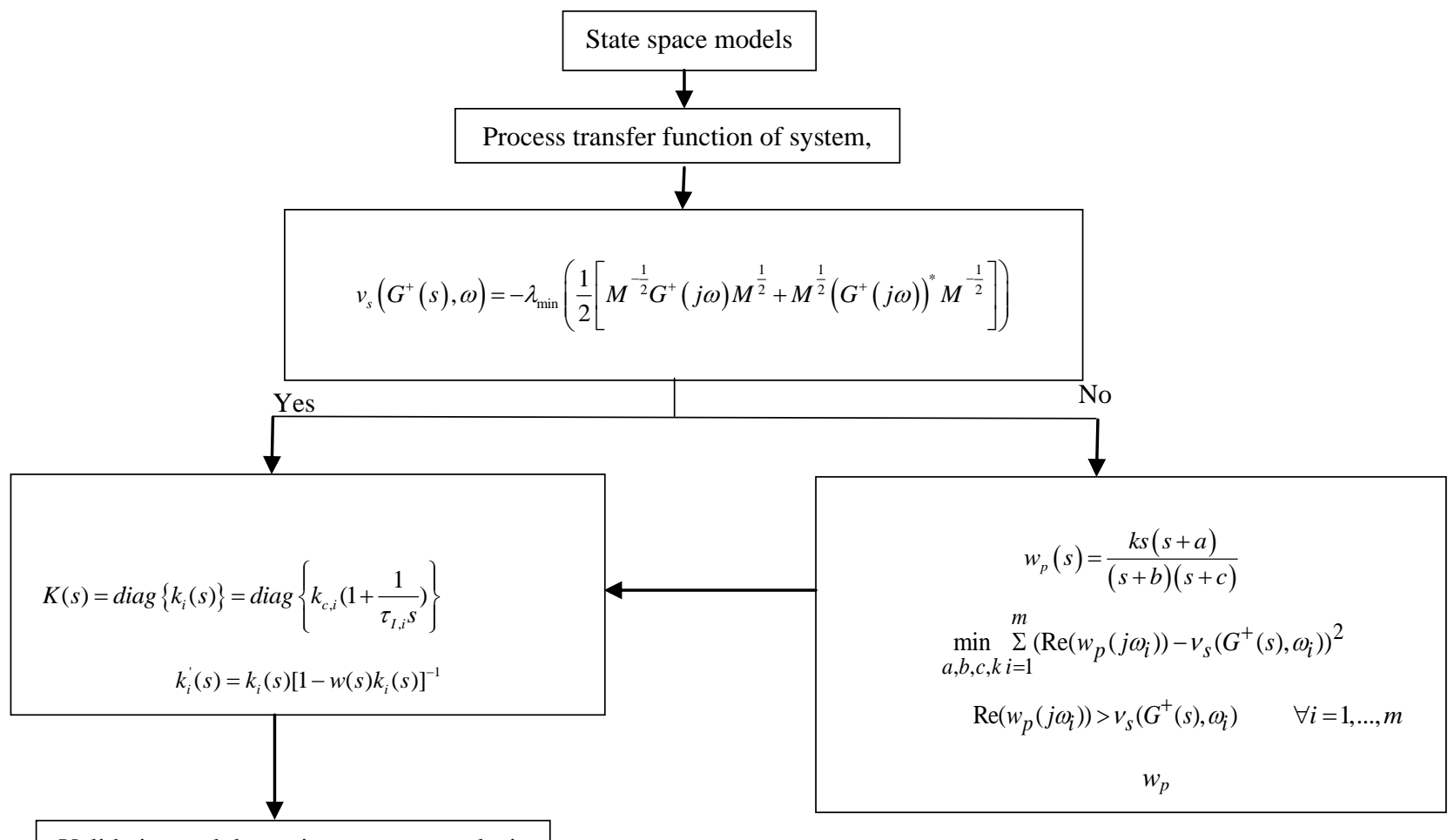

Validation and dynamics response analysis

Figure 2: The algorithm of passivity concept

First, the dynamic models of simultaneous heat and mass exchanger network are formulated from physical principles. This model as state space model can be as follow:

$$
\begin{gathered}
\dot{x}=A x+B u+E x_{0} \\
y=C x+D u
\end{gathered}
$$

Where $x \in X \subset R^{n}$ is state vector, $u \in U \subset R^{m}$ is manipulated vector, $x_{0} \in X_{0} \subset R^{k}$ is disturbance vector, $y \in Y \subset R^{j}$ is controlled vector and $A, B, C, D$, and $E$ is constant matrix. The representation $x(t)=\Phi\left(t, t_{0}, x_{0}, u\right)$ is used to denote the state at time $t$ reached from the initial state $x_{0}$ at $t_{0}[14]$.

The state space models was formulated the process transfer function matrix, $G_{p}(s)$. These processes transfer functions are analyzed by the passivity index $\left(v_{s}\right)$ which was eq. (7) to indicate that the CHAMEN were passive or not. The system is passive or stable when the passivity index is negative.

$$
v_{s}\left(G^{+}(s), \omega\right)=-\lambda_{\min }\left(\frac{1}{2}\left[M^{-\frac{1}{2}} G^{+}(j \omega) M^{\frac{1}{2}}+M^{\frac{1}{2}}\left(G^{+}(j \omega)\right)^{*} M^{-\frac{1}{2}}\right]\right)
$$

Where, $v_{s}$ is the diagonal scaling passivity index, $G^{+}(s)$ is equal to $G^{+}(s) \mathrm{U}$, $\mathrm{U}$ is a diagonal matrix with either 1 or -1 and the signs of each element are determined such that the diagonal of $G^{+}(s)$ is positive [15].

If the system was the non-passivity, it can be driven to passive region by weighting function $\left(w_{p}(s)\right)$ which was eq. (8) is added into the system in order to change non-passive system to strictly passive system. The equation 9 shows the strictly passive system $H(\mathrm{~s})$ after the system is added by weighting function. 


$$
\begin{aligned}
& w_{p}(s)=\frac{k s(s+a)}{(s+b)(s+c)} \\
& H(s)=G(s)+w p(s) I
\end{aligned}
$$

Where $a, b, c$ and $k$ are positive real parameters to be determined by solving the following optimization obtained from the passivity concept and $I$ is the identity matrix of size $\mathrm{n}$ which is the square matrix $(n \times n)$ with ones on the main diagonal and other is zeros [14].

For the multi loop control system comprising a stable subsystem $G(s)$ and a multi loop controller in eq. $10, i=1, \ldots, n$, if a stable and weighting function, $w_{p}(s)$ is chosen such as eq. 8, then the closed loop system will be stable. For any loop $i=1, \ldots, n$, the passive controllers are designed as follow:

$$
\begin{gathered}
K(s)=\operatorname{diag}\left\{k_{i}(s)\right\}=\operatorname{diag}\left\{k_{c, i}\left(1+\frac{1}{\tau_{I, i} s}\right)\right\} \\
k_{i}^{\prime}(s)=k_{i}(s)\left[1-w(s) k_{i}(s)\right]^{-1}
\end{gathered}
$$

Finally, for multi loop PI controller $\left(k_{c, j}\right.$ and $\tau_{I, i}$ ) was design based on passivity tune and compared with auto tune [15].

\section{RESULTS AND DISCUSSION}

\subsection{Methanol solvent process simulation}

The case study which is methanol solvent process has a total cost for energy $6.009 \times 10^{5}$ cost/year or 141 percentages of target. Also, the acid gas which released to the environment has to eliminate hydrogen sulfide. Thus, this work designed the combined heat and mass exchanger network to improve efficiency of the process. Moreover, the heat exchanger network and mass exchanger network were separately designed.

\subsubsection{HEN design on case study}

The process has four hot streams process which are RCHCP, WSTH2O, MixedFeed, and MixedFeed2 and three cold streams process: AZFEED, DESGS, and LPRWSF. Thus, it is easy to design HEN by using Aspen Energy Analyzer. This program analyzed the systematic of streams in the process and it has to add one hot and two cold utility streams which are $\mathrm{H} 1, \mathrm{C} 1$, and $\mathrm{C} 2$, respectively. Furthermore, all the process streams which is used for heat exchanger network design were assumed that the phase did not change. In Figure 3, it is the guideline of the heat exchanger in the process. 


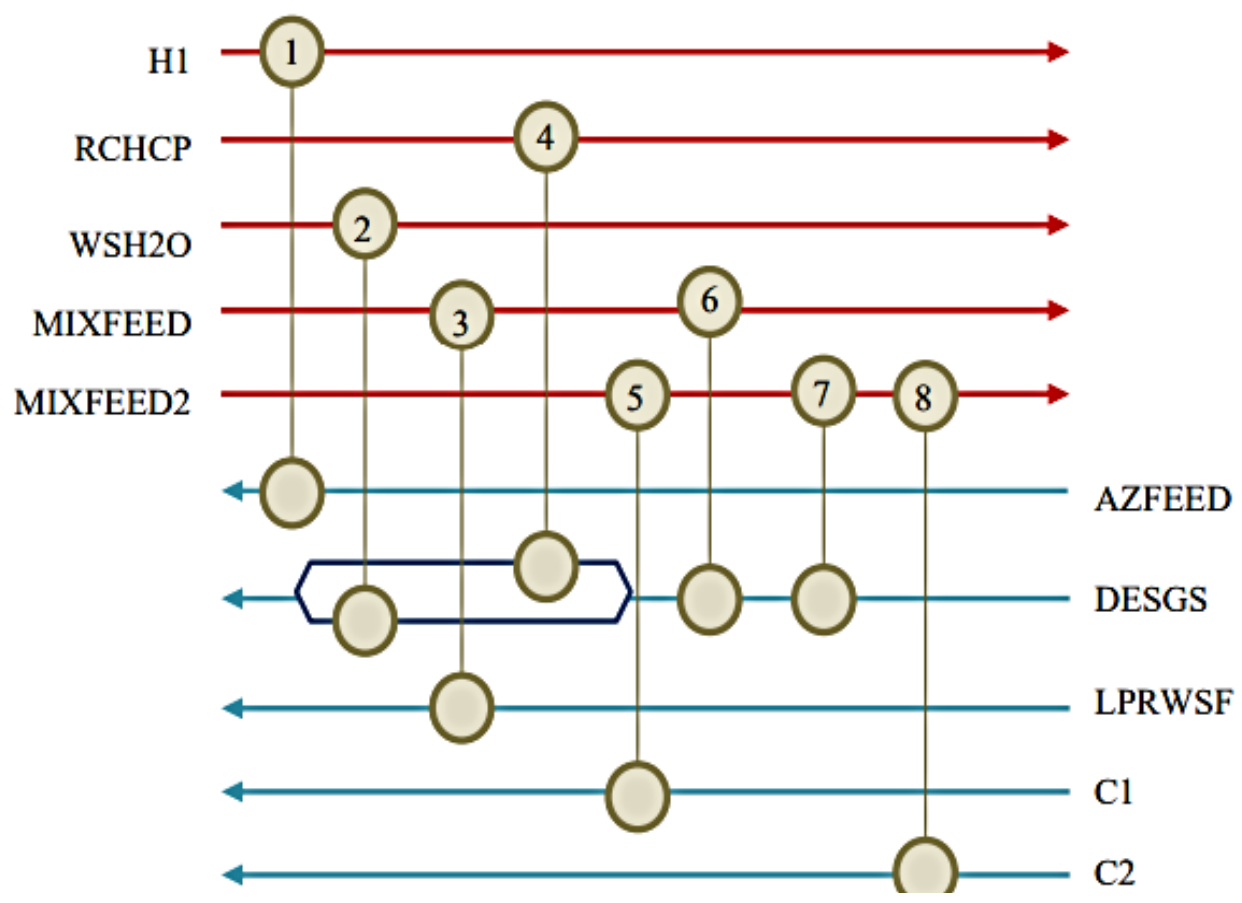

Figure 3: Grid diagram of HEN

\subsubsection{MEN design on case study}

This process has two rich and two lean streams process which are VNEX, VHTRG1, WASTE1 and WSTH2OC. Then, MEN was design base on MINLP algorithm. GAMS program used to analyze the MEN based on MINLP and the nominal condition of this system was showed in Table 1. Streams VNEX and VHTRG1 were rich of hydrogen sulfide $\left(\mathrm{H}_{2} \mathrm{~S}\right)$ which was the toxic gas. Thus, $\mathrm{H}_{2} \mathrm{~S}$ should be eliminated before release the gas to the environment. The result of mass exchanger network design as the grid diagram showed in Figure 4. The rich streams pairing only lean stream 'WSTH2OC' due to the constraint of the design.

Table 1: Streams data for combined heat and mass exchanger network

\begin{tabular}{|c|c|c|c|}
\hline Source stream & Mass rate $\mathbf{( k g / h )}$ & Source composition & Target composition \\
\hline VHTRG1 & 215.797 & 0.07914 & 0.068888 \\
\hline VNEX & 238.547 & 0.34906 & 0.174545 \\
\hline WASTE1 & 44018.2 & 0.03217 & 0.033346 \\
\hline WSTH2O & 11079.4 & 0.01155 & 0.021455 \\
\hline
\end{tabular}

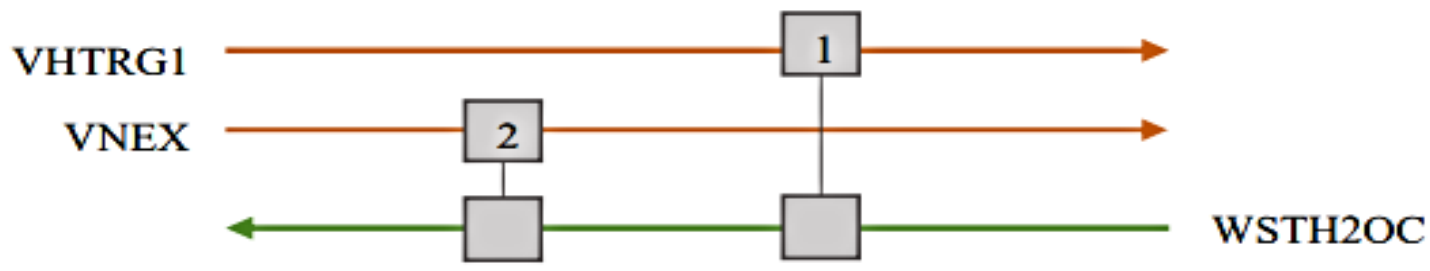

Figure 4: Grid diagram of MEN

\subsubsection{CHAMEN design on case study}

CHAMEN was presented in Figure 5 also the installation of CHAMEN in the process by Aspen Plus showed in Figure 6. After the installation of CHAMEN in the process, found that the system has a total cost of energy $4.263 \times 10^{5}$ cost/year or 98.55 percentages of the target. The methanol solvent plant with HEN showed the better result which the total cost was reduced 42 percentages of energy compares with original plant. Since heat exchangers which were 
installed can be used the energy efficiently. Moreover, this process obtained the minimization of total annual cost which was $1.536 \times 10^{5}$ cost/year for the part of MEN.

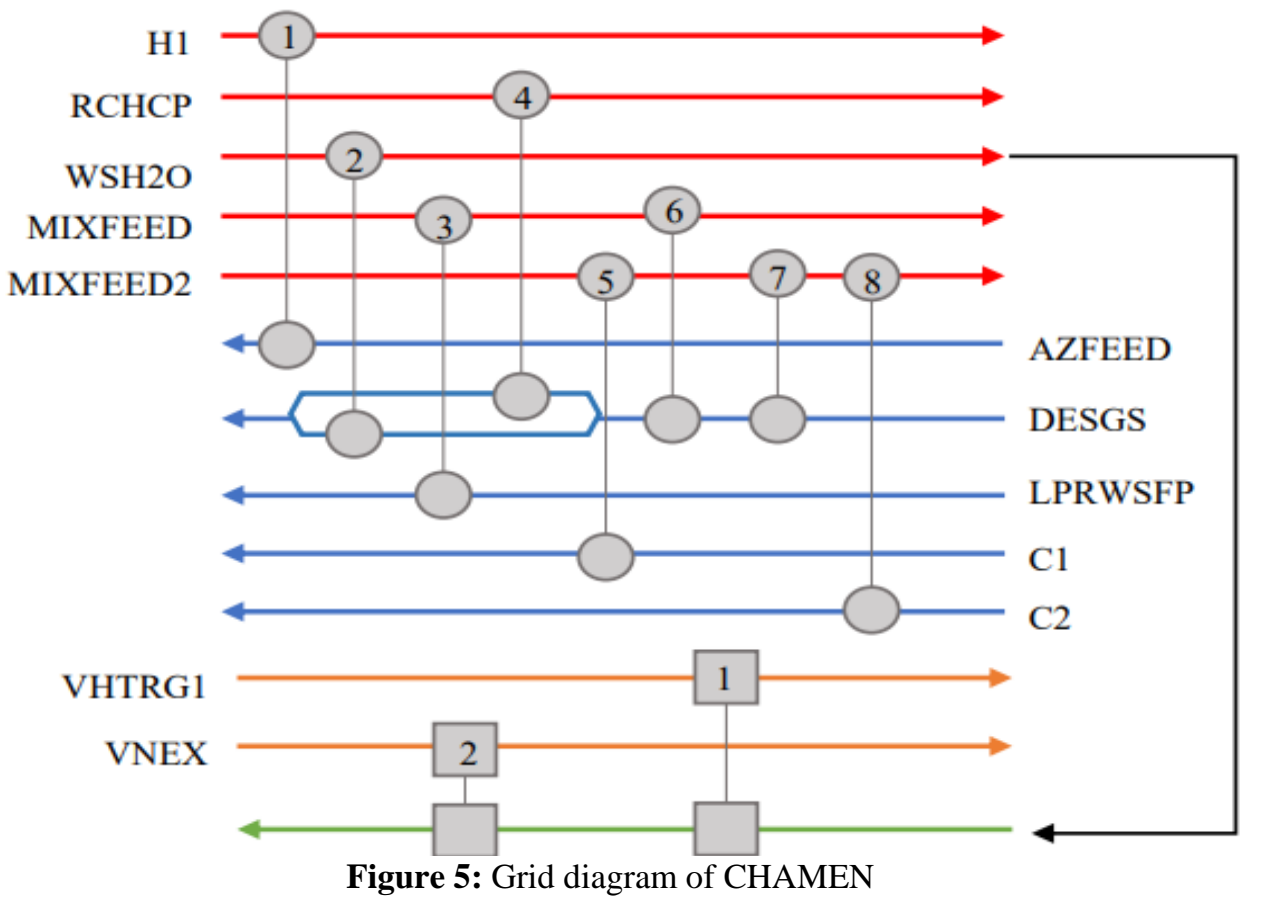

\subsection{Passivity index of CHAMEN}

The process transfer function of CHAMEN which consisted of eight heat exchangers and two mass exchangers were analyzed by using MATLAB program. In Figure 6a showed that this system was the non-passive system due to the positive value of passivity index. Thus, it has to add the weighting function to move the non-passive system into the passive system which was a negative value of passivity index. Then, this system was the passive system that means the controller stabled to control the system. Figure $6 \mathrm{~b}$ showed the passivity index after adding the weighting function (eq. 6) which can be seen that the index more too negative region.

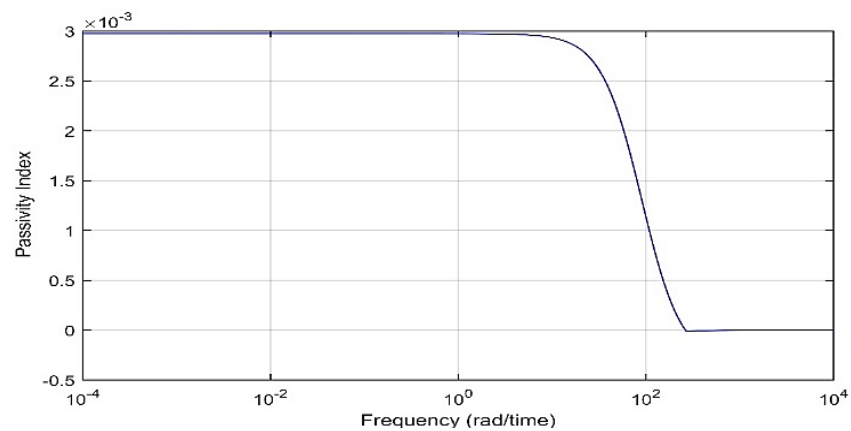

(a)

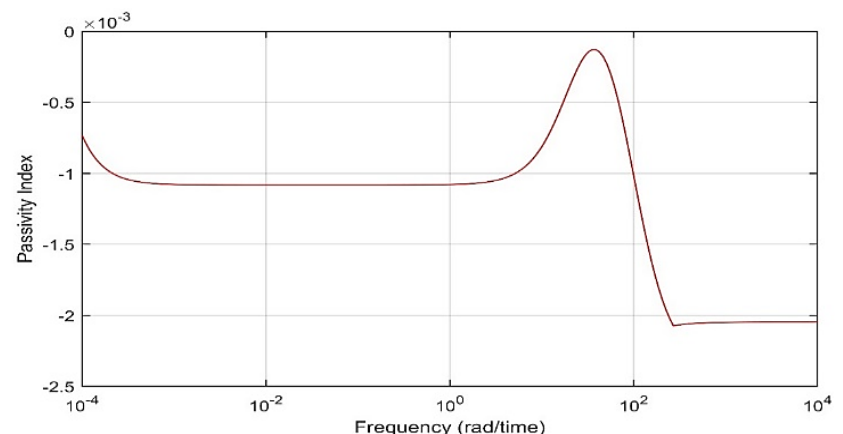

(b)

Figure 6: Passivity index of (a) CHAMEN and (b) CHAMEN with weighting function

\subsection{The responsibility of controllers in case study with CHAMEN based on auto tune and passivity tune}

For the performance of the controllers, the system was tested the dynamic by using Aspen Dynamics on pressure driven flow. Pressure driven flow is one of the dynamic models which use the pressure to adjust the flow by specific control valve opening. This dynamic model determines the flow rates by measuring both upstream and downstream pressures. This system was tested the performance by changing the flow of the feed stream which can be adjusted by specific valve opening from 50 percentages to 51 percentages at 2 hours. This system used the feedback control loop to control the process as showed in Figure 7. Also, the temperatures were controlled variable and the manipulated variables were flow of inlet streams to the heat exchangers and mass exchangers. Table 2 presented the parameters of PI controllers. 
Table 2: PI tune parameters for CHAMEN

\begin{tabular}{|c|c|c|c|c|c|c|c|}
\hline \multirow{2}{*}{$\begin{array}{c}\text { Heat/mass } \\
\text { Exchanger } \\
\text { No. }\end{array}$} & \multirow{2}{*}{$\begin{array}{c}\text { Controller } \\
\text { No. }\end{array}$} & \multirow{2}{*}{$\begin{array}{c}\text { Controlled } \\
\text { variables }\end{array}$} & \multirow{2}{*}{$\begin{array}{c}\text { Manipulated } \\
\text { variables }\end{array}$} & \multicolumn{2}{|c|}{ Auto tune } & \multicolumn{2}{c|}{ Passivity tune } \\
\cline { 5 - 8 } & 1 & $T_{C}$ & $\dot{m}_{c}$ & 6.6604 & 0.8305 & 5.9241 & 0.7657 \\
\hline 1 & 2 & $T_{C}$ & $\dot{m}_{h}$ & 45.8929 & 0.3675 & 40.5824 & 0.6669 \\
\hline 2 & 3 & $T_{C}$ & $\dot{m}_{h}$ & 34.3838 & 74.8526 & 48.8859 & 76.9194 \\
\hline 3 & 4 & $T_{H}$ & $\dot{m}_{c}$ & 23.7051 & 0.5915 & 15.3155 & 0.7572 \\
\hline 4 & 5 & $T_{H}$ & $\dot{m}_{c}$ & 53.3106 & 8.0211 & 77.5994 & 8.1397 \\
\hline 5 & 6 & $T_{H}$ & $\dot{m}_{c}$ & 11.1257 & 6.5111 & 20.7189 & 7.1185 \\
\hline 6 & 7 & $T_{C}$ & $\dot{m}_{h}$ & 18.2661 & 28.1888 & 24.7069 & 15.6512 \\
\hline 7 & 8 & $T_{H}$ & $\dot{m}_{c}$ & 162.7549 & 0.8965 & 152.9058 & 0.7779 \\
\hline 8 & 9 & $y_{1}$ & $\mathrm{~L}_{2}$ & 48.2714 & 29.6775 & 19.2236 & 10.5020 \\
\hline 1 & 10 & $y_{2}$ & $\mathrm{~L}$ & 82.3389 & 44.8287 & 13.6497 & 11.5347 \\
\hline 2 & & & & & & & \\
\hline
\end{tabular}

In the part of auto tune, these parameters were used for tune the controllers in Aspen Dynamic. The result presented in Figures 8-9. From these graphs, all of the controllers cannot be reach the set points because the PI auto tune parameters did not suitable for this process although the valve tried to adjust the flow of inlet streams.

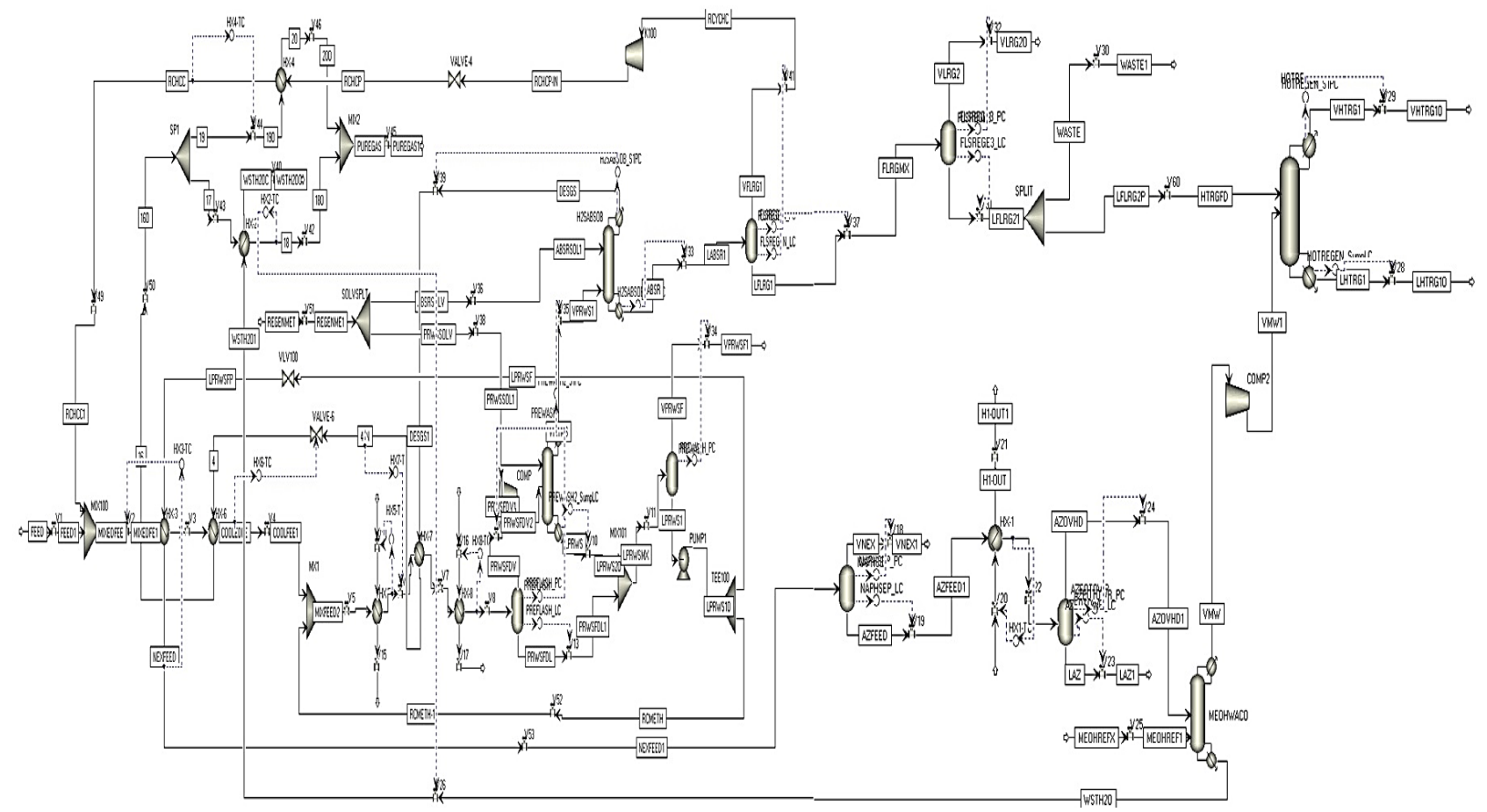

Figure 7: The controllers in case study with CHAMEN 


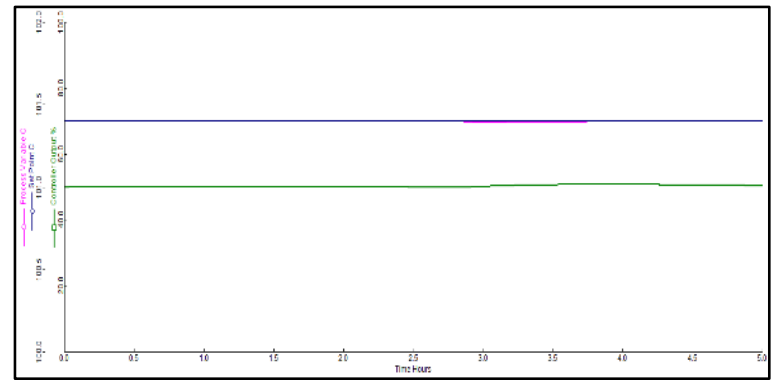

(a)

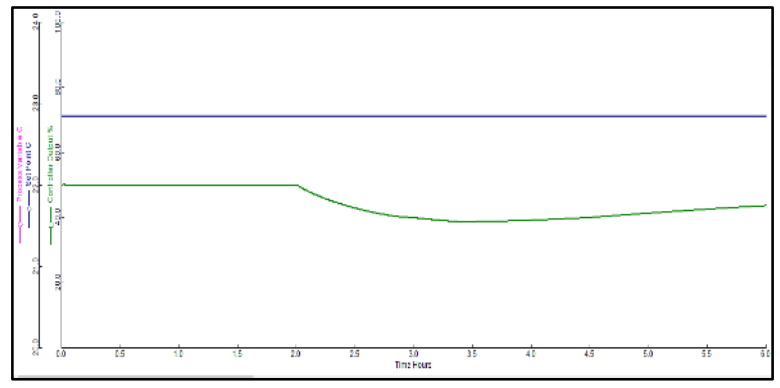

(c)

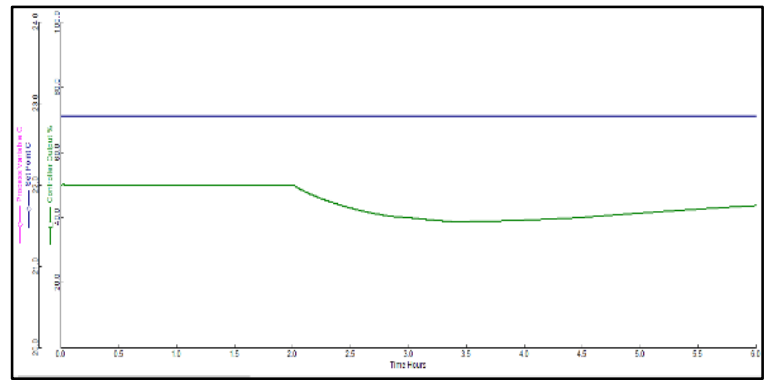

(b)

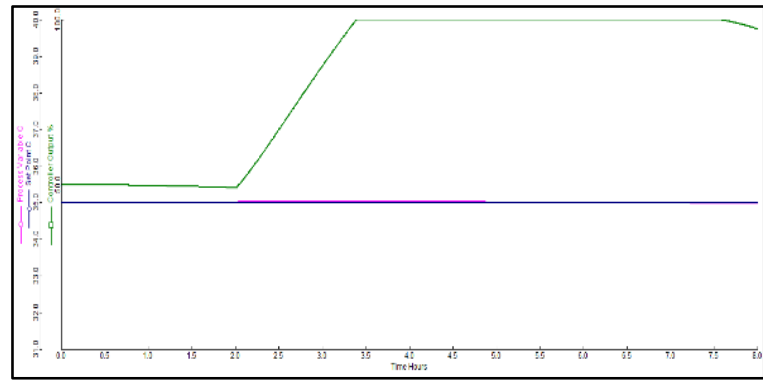

(d)

Figure 8: The responsibility of (a) controller 1, (b) controller 2, (c) controller 3 and (d) controller 4 by disturbance changed at 2 hours based on auto tune in CHAMEN

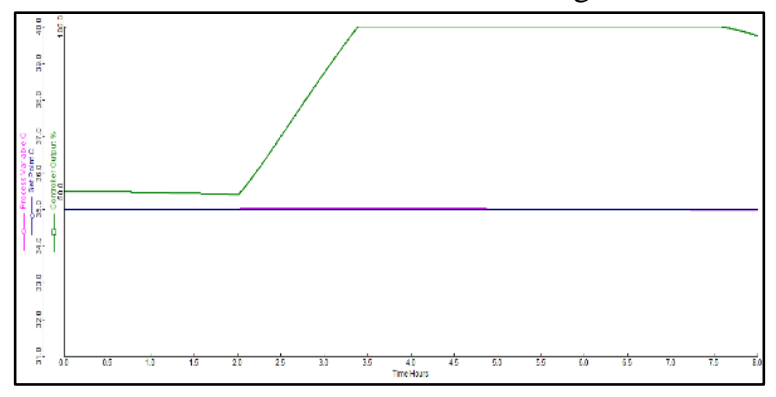

(a)

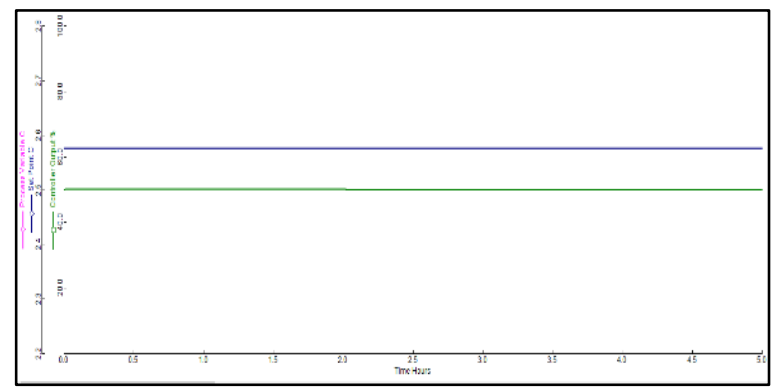

(c)

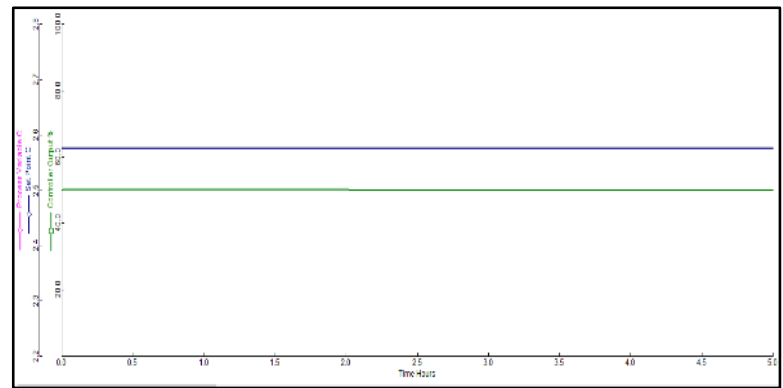

(e)

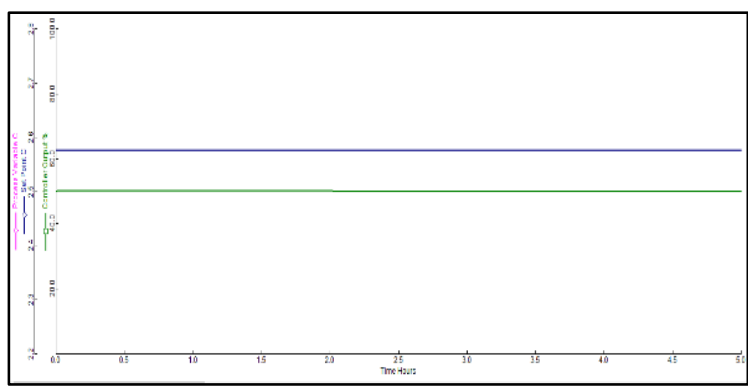

(b)

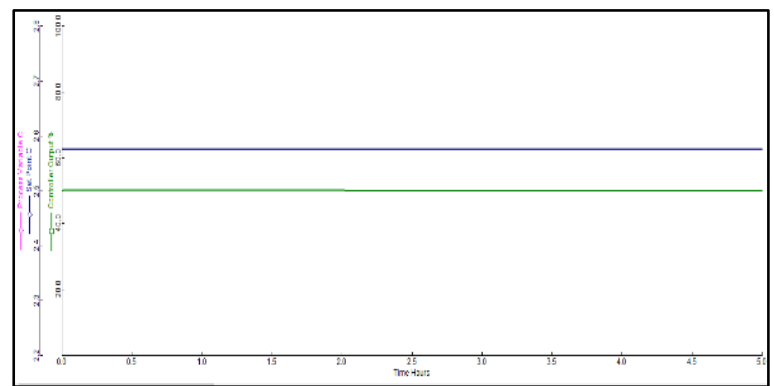

(d)

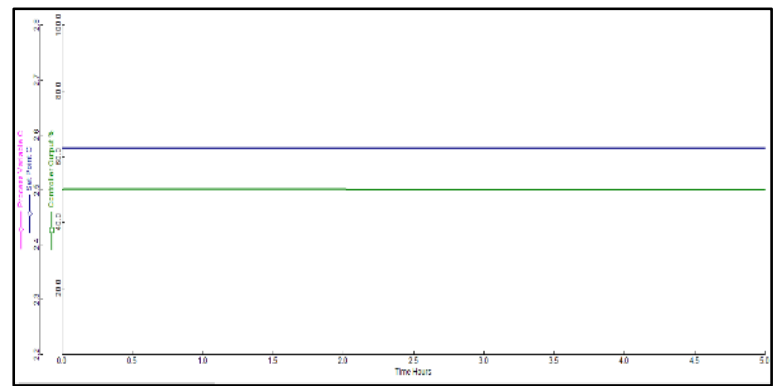

(f)

Figure 9: The responsibility of (a) controller 5, (b) controller 6, (c) controller 7, (d) controller 8, (e) controller 9 and (f) controller 10 by disturbance changed at 2 hours based on auto tune in CHAMEN 
From auto tune method, some of the controllers reached the set points but other not. The controllers 1, 2, 4, 5, 6, 7, 8, and 10 reached the set points at 3.75, 3.38, 7.12, 7.55, 2.28, 5.8, 2.24 and 6.95 hours, respectively. However, this system has two controllers (controllers 3 and 9) which have an offset. Therefore, the changed of the feed flow has an effect on process variable.

In the part of passivity tune, Figures 10-11 were represented the responsibility of hot and cold stream also rich streams which obtained from combined heat and mass exchanger network in the case study.

The performance of most of the controller based on passivity tune reached the set points excepting the controller 9 which has an offset. The controllers $1,2,3,4,5,6,7,8$, and 10 was reached the set points at 3.84, 2.06, 3.91, 5.39, 6.15, $2.15,2.88,2.09$, and 3.78 hours, respectively. On the other hands, controller 9 did not reach the set points due to the sensitive of the stream and less mass flow rates. Furthermore, the results from passivity tune were better than auto tune. Because passivity tune reach the set points fast, smoothly and not overshoot.

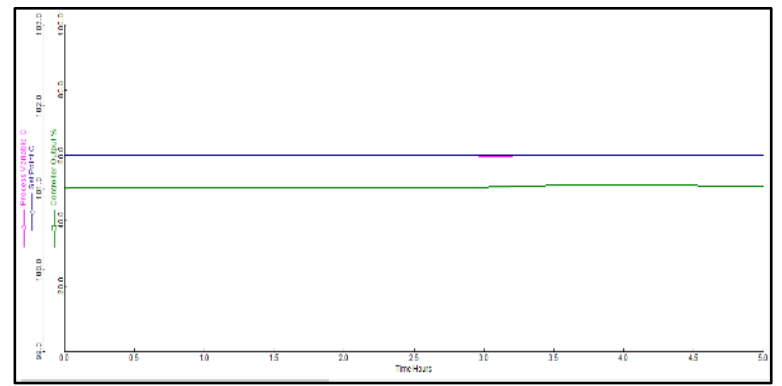

(a)

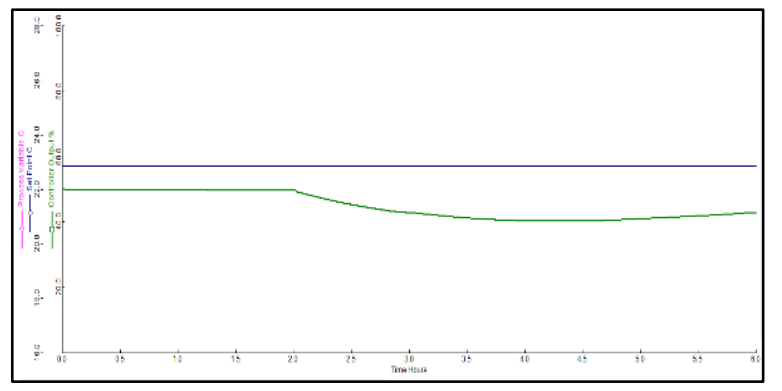

(c)

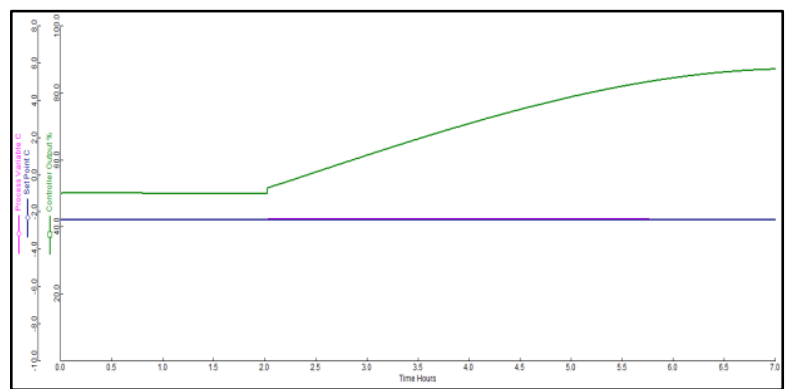

(e)

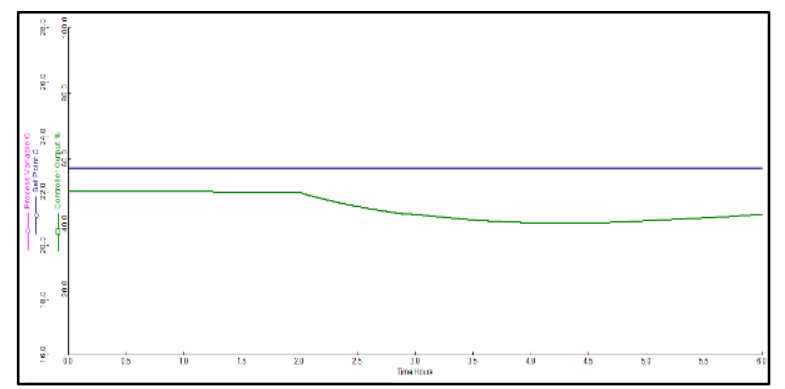

(b)

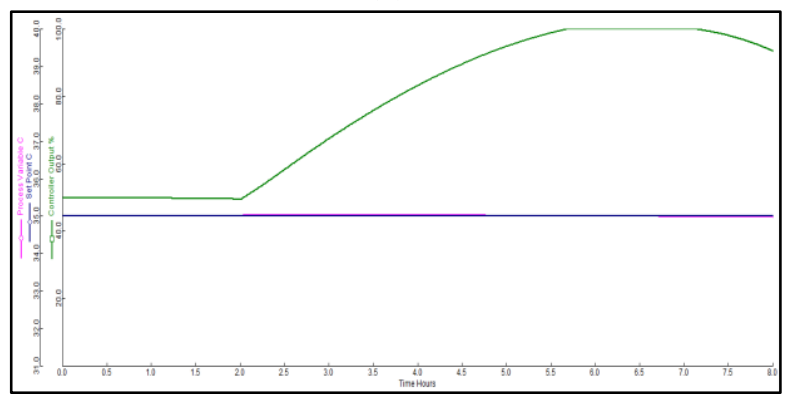

(d)

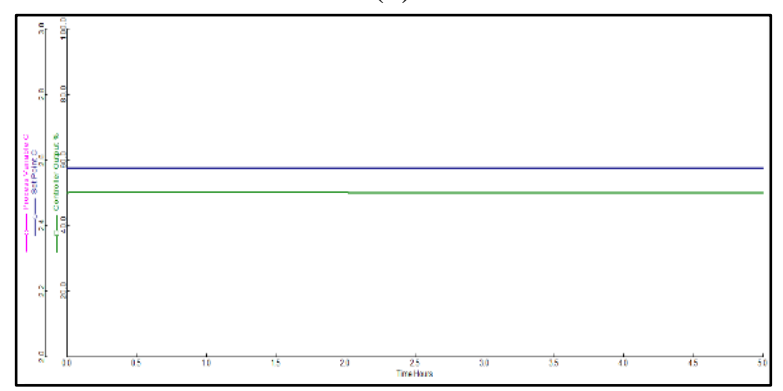

(f)

Figure 10: The responsibility of (a) controller 1, (b) controller 2, (c) controller 3, (d) controller 4, (e) controller 5 and (f) controller 6 by disturbance changed at 2 hours based on passivity tune in CHAMEN 


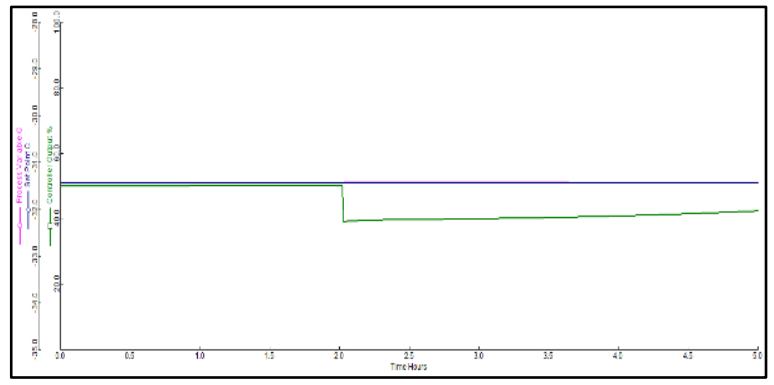

(a)

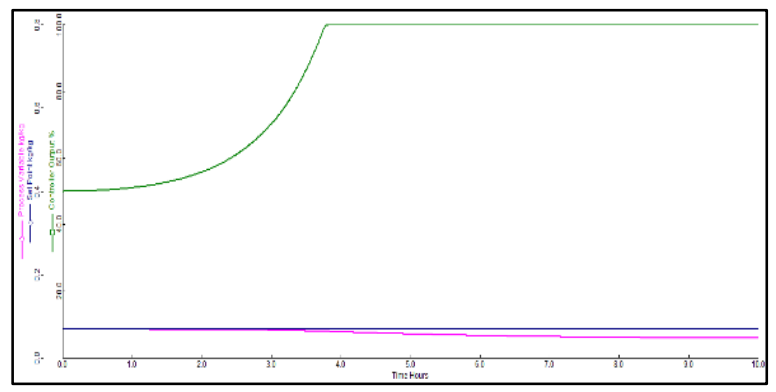

(c)

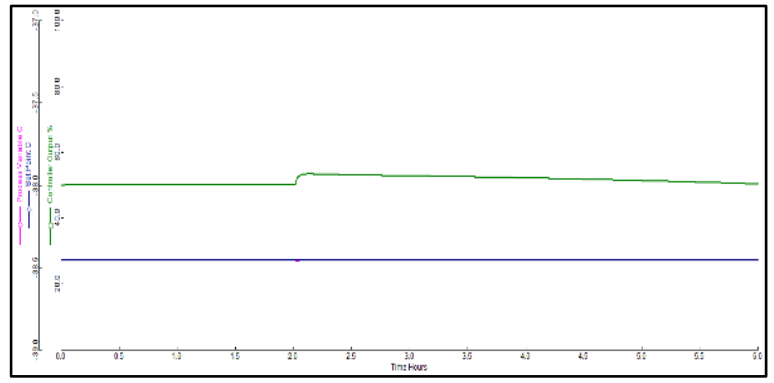

(b)

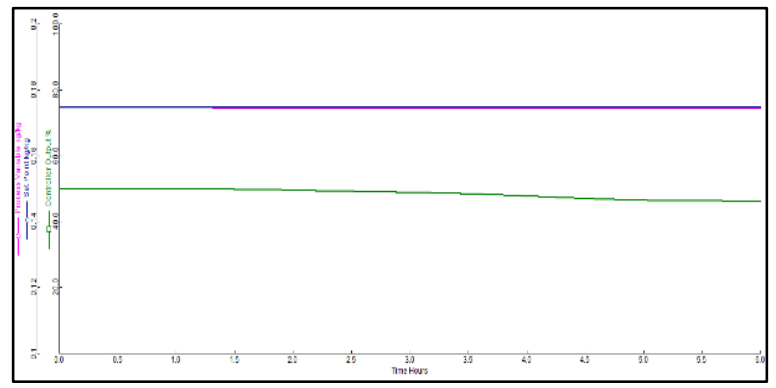

(d)

Figure 11: The responsibility of (a) controller 7, (b) controller 8, (c) controller 9 and (d) controller 10 by disturbance changed at 2 hours based on passivity tune in CHAMEN

\section{CONCLUSIONS}

The Methanol solvent process was used as a case study for installing the CHAMEN. This was created in Aspen plus after the designing of heat exchanger network in Aspen Energy Analyzer and mass exchanger network in GAMS. Thus, the network cost index, network performance, and minimum total annual cost were performed. The system with and without installing the controllers was tested. Also, the passivity concept and auto tune method were applied in the case study. The result from the process with only HEN showed that the total cost per year of the process was $4.263 \times 10^{5}$ cost/year or 98.55 percentages of the target. However, this case study with CHAMEN was used more energy. The process with HEN and CHAMEN represented the same trend or the results that the system without controllers showed the worse results than with controllers. Moreover, the passivity tune showed the better results than auto tune method.

\section{ACKNOWLEDGEMENT}

This research has been supported by Center of Excellence on Petrochemical and Materials Technology and Department of Chemical Engineering, Faculty of Engineering. Also, the Graduated School, Kasetsart University.

\section{REFERENCES}

[1] Juan, G. S., and Adrián, B.,"Process Intensification in Heat and Mass Exchanger Networks", Process Intensification in Chemical Engineering, 2016.

[2] Isafiade, A.J., and Fraser, D.M., "Optimization of Combined Heat and Mass Exchanger Networks Using Pinch Technology", Asia-Pac. J. of Che. Eng., vol. 2, no. 6, pp. 554-565, 2007.

[3] Isafiade, A.J., and Fraser, D.M., "Interval Based MINLP Superstructure Synthesis of Combined Heat and Mass Exchanger Networks", Chem. Eng. Res. Des., vol. 87, no. 11, pp. 1536-1542, 2009.

[4] Martin, L.L., and Manousiouthakis, V., "Total Annualized Cost Optimality Properties of State Space Models for Mass and Heat Exchanger Networks”, Chem. Eng. Sci., vol. 56, no. 20, pp. 5835- 5851, 2001.

[5] Azeez, O.S., Isafiade, A.J., and Fraser, D.M., "SupplyBased Superstructure Synthesis of Heat and Mass Exchange Networks", Comput. Chem. Eng., vol. 56, pp. 184-201, 2013.

[6] Boonkhao, B., Srinophakun, T., and Sirisak, R., "Controllability Studies of Chemical Processes Based on the Concept of Passivity”, Kasetsart J., vol. 42, pp. 137-148, 2008.

[7] Lenhoff A.M., and Morari, M., "Design of Resilient Processing Plants-I Process Design under Consideration of Dynamic Aspects”, Chem. Eng. Sci., vol. 37, no. 2, pp. 245-258, 1982. 
[8] Bristol, E. H., "On a new measure of interaction for multivariable process control”, IEEE T. Automat. Contr., vol. 11, pp. 133-134, 1996.

[9] Lewin, D. R., “A simple tool for disturbance resiliency diagnosis and feedforward control design”, Comput. Chem. Eng., vol. 20, no. 1, pp. 13-25, 1996.

[10] Bao, J., and Lee, P.L., "Process Control: The Passsive Systems Approach Advanced in Industrial Control”, London, UK, 2007.

[11]Denis, L. W., Brent, R. Y., and William, Y. S., “A Controllability Index for Heat Exchanger Networks”, Ind. Eng. Chem. Res., vol. 42, no. 20, pp. 4659-4667, 2003.

[12] Dai, C., Wei, W., Lei, Z., and Chen, B., "Absorption of CO2 with Methanol and Ionic Liquid Mixture at Low Temperatures", Fluid Phase Equilibria, vol. 391, pp. 9-17, 2015.

[13] Seo, M. W., Yum, Y. M., Cho, W. C., Ra, H. W., Yoon, S. J., Lee, J. G., Kim, Y.K., Kim, J. H., Lee, S. H., Eom, W. H., Lee, U. D., and Lee, S. B., "Methanol Absorption Characteristics for the Removal of H2S (hydrogen sulfide), COS (carbonyl sulfide) and CO2 (carbon dioxide) in a Pilotscale Biomass-to-liquid Process", Energy, vol. 66, pp. 56-62, 2014.

[14] OMICS International, www.omicsonline.org, UK.

[15] Wen, Z. Z., Jie, B., and Peter, L. L., "Decentralized Unconditional Stability Conditions Based on the Passivity Theorem for Multi-loop Control Systems", Ind. Eng. Chem. Res., vol. 41, pp. 1569-1578, 2002.

[16] Jie, B., and Peter L. L., "Passivity-based Fault-tolerant Control", Advances in Industrial Control, 2007. 